\title{
I am Becoming a Doctor: Mine or Someone Else's Will? Or Does it Even Matter? A Qualitative Investigation
}

\author{
Chan Choong Foong ${ }^{1^{*}}$, Nik Nadia Nik Nazri ${ }^{1}$, Nurul Atira Khairul Anhar Holder ${ }^{1}$ \\ ${ }^{1}$ Medical Education and Research Development Unit, Faculty of Medicine, University of Malaya, Kuala Lumpur, MALAYSIA
}

Received 30 January 2018 • Revised 17 April 2018 • Accepted 5 May 2018

\begin{abstract}
This study explored the motivation of underperforming students at three points of time: applying the programme, studying in Year 1 and during their repeating year due to academic failure. Six underperforming Year 1 students were interviewed on their initial motivations for choosing the medical programme. Triangulation of analysts was applied in the narrative analysis. Later, these students completed the Academic Motivation Scale (AMS) questionnaire twice to reflect on their learning experience in Year 1 and their repeating year. Results showed that these students initially had a mix of amotivation, intrinsic motivation and extrinsic motivation upon applying the medical programme where the worst case scenario was that students genuinely "did not know why". It was further shown that their motivation for studying medicine was unchanged, increased or decreased over a period of time. Although this study fails to support the notion that initial motivation matters in influencing academic success, the AMS results proved that student motivation could also change over time. Hence, more effort is needed to nurture intrinsic motivation after enrolling into medical schools.
\end{abstract}

Keywords: medical education, underperforming students, motivation, changes of motivation, interview

\section{INTRODUCTION}

Motivation is essential for students to succeed in their studies and careers. Initial motivations of students for choosing the medical programme and possible changes of motivation for studying medicine over a period of time are the focuses of the study.

\section{Initial Motivations of Students for Choosing the Medical Programme}

Past studies investigated initial motivations of students for choosing the medical programme. We summarised these past findings into types of motivation following the Self-Determination Theory (Deci \& Ryan, 2000, 2008; Ryan \& Deci, 2000a, 2000b) (Table 1). Motivation is a self-determination continuum. There are three types of motivation, namely intrinsic motivation, extrinsic motivation and amotivation. Intrinsic motivation is defined as motivation perceived from within oneself. Three subtypes of intrinsic motivation are the motivation to know, motivation towards accomplishment and motivation to experience stimulation.

Student intrinsic motivation for choosing a medical programme from previous studies includes: (a) altruism (desire to help people, giving back to society), (b) interest in Science/Biology and (c) vocation. Extrinsic motivation is defined as motivation perceived from the external environment or outside of oneself. The four subtypes of extrinsic motivation are external regulation, introjected regulation, identified regulation and integrated regulation. Past studies that have dealt with student extrinsic motivation for choosing a medical programme includes: (a) parents or family expectation/pressure, (b) monetary gain, (c) prestigious profession, (d) good academic results, (e) illness/death in the family, (f) maintaining self-worth and (g) career prospects. Amotivation is defined as having the lack of intention or motivation to do a particular action, where it is neither regulated by external nor internal

(C) 2018 by the authors; licensee Modestum Ltd., UK. This article is an open access article distributed under the terms and conditions of the Creative Commons Attribution License (http://creativecommons.org/licenses/by/4.0/). $\square$ foongchanchoong@um.edu.my (*Correspondence) $\square$ niknadia91@um.edu.my $\square$ nurul_atira@um.edu.my 


\section{Contribution of this paper to the literature}

- To date, the possible changes of motivation for studying medicine over a period of time have been limitedly explored and discussed.

- $\quad$ This study explores the Eastern perspective and discussed the Western versus Eastern contexts.

- This study suggests that student motivation may shift over a period of time, and more effort is required to nurture intrinsic motivation after students enroll into medical schools.

Table 1. Past studies on initial motivations of students for choosing the medical programme

\section{Types of Motivation \\ Extrinsic Motivation}

(a) Parents or family expectation/pressure

(Al-Hemiary, Al-Nuaimi, Al-Saffar, \& Randall, 2017; Diwan,

Minj, Chhari, \& De Costa, 2013; Rashmi A Kusurkar, Croiset, Galindo-Garré, \& Ten Cate, 2013; McHarg, Mattick, \& Knight, 2007; Pruthi et al., 2013; Shankar, Singh, Gautam, \& Dhaliwal, 2013)

(b) Monetary gain

(Crossley \& Mubarik, 2002; Győrffy, Birkás, \& Sándor, 2016; Heikkilä et al., 2015; Hyppölä et al., 1998; Rashmi A Kusurkar et al., 2013; McHarg et al., 2007; McHugh et al., 2011; Skatova (i) \& Ferguson, 2014)

(c) Prestigious profession

(Diwan et al., 2013; Girasek, Molnár, Eke, \& Szócska, 2011; Győrffy et al., 2016; Heikkilä et al., 2015; Hyppölä et al., 1998; Khami, Murtomaa, Jafarian, Vehkalahti, \& Virtanen, 2008; (j) Rashmi A Kusurkar et al., 2013; Skatova \& Ferguson, 2014)

(d) Good academic results (Vaglum, Wiers-Fenssen, \& Ekeberg, 1999)

(e) Illness/death in the family (Győrffy et al., 2016; Hyppölä et al., 1998; McHarg et al., 2007)

(f) Maintaining self-worth (Wouters, Croiset, Isik, \& Kusurkar, 2017)

(g) Career prospects

(Ayuob, Bahumdain, AL-Najei, Khobrani, \& El Deek, 2015; Crossley \& Mubarik, 2002; Girasek et al., 2011; Győrffy et al., 2016; Heikkilä et al., 2015; Hyppölä et al., 1998; Pagnin et al., 2013; Skatova \& Ferguson, 2014)

\section{Intrinsic Motivation}

(h) Altruism (desire to help people, giving back to society) (Al-Hemiary et al., 2017; Ayuob et al., 2015; Crossley \& Mubarik, 2002; Diwan et al., 2013; Gąsiorowski, Rudowicz, \& Safranow, 2015; Girasek et al., 2011; Győrffy et al., 2016 Heikkilä et al., 2015; Hyppölä et al., 1998; Rashmi A Kusurkar et al., 2013; McHarg et al., 2007; McHugh et al., 2011; Molnár, Nyári, Hazag, Csinády, \& Molnár, 2008; Pagnin et al., 2013; Pruthi et al., 2013; Puljak, Kraljevic, Latas, \& Sapunar, 2007; Skatova \& Ferguson, 2014; Vaglum et al., 1999)

Interest in Science/Biology (Crossley \& Mubarik, 2002; Gąsiorowski et al., 2015; Girasek et al., 2011; Győrffy et al., 2016; Rashmi A Kusurkar et al., 2013; McHugh et al., 2011; Pagnin et al., 2013; Puljak et al., 2007)

Vocation

(Al-Hemiary et al., 2017; Heikkilä et al., 2015; Hyppölä et al., 1998)

factors. Students' initial motivation that is classified as amotivation for choosing a medical programme was not found in past literature.

Understanding on motivation is essential as motivation influences the educational outcomes of the students, including their perseverance in their studies, academic success, learning behaviour, career satisfaction and career choices (Kusurkar, Ten Cate, van Asperen, \& Croiset, 2011). There has been evidence indicating a significant relationship between motivation and academic success (Yousefy, Ghassemi, \& Firouznia, 2012) where high intrinsically and high extrinsically motivated students performed significantly better than those with lower motivations (Shrestha \& Pant, 2018). Although there has been a number of studies on this matter, there have been null studies in the Malaysian context in the past ten years (Goel, Angeli, Dhirar, Singla, \& Ruwaard, 2018).

Three decades ago, two quantitative studies identified the main initial motivations among Malaysian students, which were genuine interest and the desire to help people (Parameshvaradeva, 1981; Shahabuddin, 1986). An unhealthy trend emerged later in 1996 where it was revealed that some students chose the medical programme due to family influence and monetary gains (Razali, 1996). Consequently, the same study also reported that $19 \%$ of clinical students thought it was the wrong choice for choosing the medical programme. Despite this, there is still a continuation in the unhealthy trend of choosing the medical profession for extrinsic reasons. In a country where the medical profession is seen as highly prestigious in society (Cruez, 2014; Lee, Foong, Choon, \& Jamuna, in press; Yusoff, Rahim, Baba, \& Esa, 2011), provides job security and pays well, these are promising incentives.

Furthermore, with more medical doctors reluctant to work in rural areas, researching into motivation is essential as motivated doctors would have more enthusiasm in putting forth and initiating efforts to improve the healthcare services in the country (Goel et al., 2018). Developing countries such as Malaysia would encounter more 
severe inequitable distribution of doctors between the urban and rural areas, where one of the reasons is most likely due to poor motivation (Hurst, 2014). Multiple public discourses in the media have addressed this matter and it was postulated that lack of interest and passion are the main reasons doctors are quitting their housemanship (i.e., two-years training programme after graduation, otherwise known as internship or foundation in some countries), mainly due to their initial motivation in fulfilling parents' expectations. However, there is still a lack of research evidence to back up or refute this belief. Although there have been past studies in other countries which question the motivation of students applying to study medicine, it was found that results vary across different countries or cultures (Woodward, Thomas, Jalloh, Rees, \& Leather, 2017), thus further cementing the need to carry out this study.

Therefore, in the Malaysian context, this study would like to answer the following research questions: What were the initial motivations of Year 1 underperforming students for choosing the medical programme? Were they intrinsically motivated? To the best of our knowledge, we may represent the first qualitative study investigating initial motivations of underperforming medical students in Asia.

\section{Possible Changes of Motivation for Studying Medicine over a Period of Time}

Table 1 clearly indicates that students it is unnecessary for students to be intrinsically motivated to become medical doctors. Since intrinsic motivation to study medicine helps students to appreciate their profession and increase their career satisfaction, we are concerned if the motivation to study medicine would be dynamic and fluctuating. Is there a possibility motivation to study medicine can change? Such argument is important because if motivation could change over a period of time, intrinsic motivation could be nurtured to promote deep learning, better academic performance and positive well-being (Kusurkar et al., 2011). To date, possible changes of motivation for studying medicine over time have been limitedly explored and discussed (An et al., 2017). Del-Ben et al. (2013) attempted to answer this question. Discouragingly, their findings showed that motivation of Year 1 students reduced throughout their academic year.

It should also be noted that motivation is a process and a continuum where amotivation or extrinsic motivation could develop into intrinsic motivation or vice versa (Feri, Soemantri, \& Jusuf, 2016; Ryan \& Deci, 2000). Therefore, this study would like to answer the following research questions: How was the motivation of Year 1 underperforming students during their first attempt (studying in Year 1) and their second attempt (during their repeating year)? Did their motivation change?

\section{METHODOLOGY}

\section{Context of the Study}

Qualitative studies allow meaning to emerge from the data. The initial plan of a larger study that we conducted was to explore the possible causes of academic failure among underperforming medical students. However, as this larger study progressed, initial motivations of students for choosing the medical programme had caught our attention as there was a mix of genuine and non-genuine motivations. As these underperforming students were repeating Year 1, we also monitored their motivation to study medicine as a part of an intervention. We are remedial coaches for student support in the medical programme. We have medical or education qualifications, and we have received training in conducting education research.

Prior to their admission to this medical school, these underperforming students had scored the maximum cumulative grade point average at their pre-university level and performed satisfactorily in the admission interview. After enrolling into this medical school, they were engaged in an integrated curriculum in which Year 1 consists of Language in Medicine, Foundation of Medical Sciences, Musculoskeletal Sciences, Cardiovascular Sciences and Respiratory Sciences. Students were required to participate in weekly problem-based learning sessions and clinical exposures. At the end of Year 1, these students were unable to perform satisfactorily in all assessments, where they either failed the knowledge or clinical assessments, or both. Upon repeating Year 1 (i.e. second attempt), they were required to undergo all the teaching and learning sessions and assessments once again the following year.

Target population of the study was all underperforming medical students who were repeating Year 1 in our institution. In the academic session 2016/2017, there were six underperforming students who failed their Year 1 studies (i.e. first attempt) and they were required to repeat the year (i.e. second attempt). All six underperforming students consented to participate in the study where the sample was the population. Meanwhile, in this case study, these informants represented typical cases of underperforming students where obtaining their experiences would be informative in comprehending other underperforming students in our institutions, which share similarities with the context of this study (Yin, 2003). 


\section{Procedures of Data Collection}

Ethical approval was obtained from the institution. We conducted a meeting with all Year 1 underperforming students at the beginning of their repeating year. These students had been in the medical programme for one year, but we did not have any prior personal relationship established with them. In the meeting, students were explained on the purpose, possible benefits and ethics of this study. Their participation was completely voluntary and they were allowed to withdraw at any time. It was also explained to the students that their honest responses in the interviews and questionnaires would not affect their future academic results. Using this data, they were to be guided to reflect on their initial motivations for choosing the medical programme and possible causes of their academic failure. These efforts were expected to encourage students in expressing their honest responses and the students were reassured on the ethics of the present study.

Upon obtaining the signed written consents, an interview was scheduled for students individually. Results from the interviews informed of the motivation of the underperforming students at the time of applying to the medical programme. At times, using interviews are the only way to get hold of data to explain a particular phenomenon and is "necessary when we cannot observe behaviour, feelings or how people interpret the world around them" (Merriam, 2009). The interview was semi-structured and the same question was asked to each student at the beginning of the interview: "Why did you choose to study medicine?" in order to better comprehend their initial motivations for choosing the medical programme. Following the initial questions, students were challenged or prompted on their responses for choosing medicine such as "You wanted to help people. But nurses help other people as well. So, why did you not choose to become a nurse?" From here, more questions were asked for probing based on the answers given by the students. The interview questions were piloted with under perfoming students from the previous academic session. Each interview lasted approximately 60 to 90 minutes and it was audiorecorded. The first author conducted the interviews. The interviews were conducted in an interview room with minimal disruption from noise and people, so that the students felt safe to share. No repeat interview was conducted.

In medical schools, the Academic Motivation Scale (AMS) was used to compare students' motivation over a period of time (Del-Ben et al., 2013). In this study, the underperforming students completed the AMS questionnaire where they were asked to reflect on their motivation for studying in Year 1. Six months later, we conducted another meeting to monitor the well-being and progress of these students. At this time, they completed the AMS questionnaire for the second time to report on their motivation during the repeat year (i.e. second attempt). AMS is a validated questionnaire first developed by Vallerand and colleagues in 1989 (Schutte et al., 2017) and is based on the conceptual framework of the Self-Determination Theory (Deci \& Ryan, 2000, 2008; Ryan \& Deci, 2000a, 2000b). This instrument consists of 28 items scored on a 7-point Likert scale (Vallerand et al., 1992, 1993).

\section{Analysis of Data}

Each interview was transcribed verbatim. Two data analysts analysed the interviews and a narrative analysis approach (Riessman, 2005) was used where we applied the use of 're-storying' which are stories from the students, presented in the researchers' own words. There was also a general process to identify an attribute for a portion of the data according to their initial motivation to study medicine. Subsequently, codes such as "monetary gain" and "illness in the family" were created and as similarities were identified, these two codes were categorized under the category of intrinsic motivation, extrinsic motivation and amotivation, as per guided by the Self-Determination Theory.

To further comprehend motivation of these underperforming students to study medicine after enrolling to this medical school, a comparison of their AMS results before and after six months were made. Radar charts were used to clearly illustrate the possible changes of motivation of these students over a period of time.

\section{RESULTS}

\section{Initial Motivations of Students for Choosing the Medical Programme}

In the present study, there were three male and three female Year 1 underperforming medical students. These students were given female pseudonyms of Alice, Bella, Catherine, Diana, Elizabeth and Fiona to prevent identifiable data.

\section{Alice}

Alice is a 19 year old student. The interview began with the question, "Why did you choose to study medicine?" Alice first mentioned of her personal experiences. Alice had always been afraid of clinics and hospitals when she 
was a young girl. However, she met a kind doctor who was involved in her operation and this doctor eventually inspired her to pursue a career in the field of medicine.

"He [the doctor] was actually encouraging me not to worry about the operation and all that stuff. So one of the reasons that encouraged (me) to enroll into medical school was him." (A, Line 6, Interview)

Alice also expressed her desire to help people. She mentioned that she has "a high affinity towards helping people" (A, Line 40, Interview) and that she cares "too much for people." (A, Line 40, Interview) Coupled with her father having psoriasis, she decided to pursue the medical field even more as she wishes to help her father get better and help as many people as she can in the process.

Although Alice sounded confident with her answers at the beginning of the interview, when pressed for further clarification, she seemed to be unsure of her answers and altered some of the points she said earlier.

"...my father said go take medicine. So I took medicine." (A, Line 86, Interview)

With her father being a dominant figure in the family and having a close rapport with Alice, she mentioned of her father's wish for her to take medicine in university. Without an ambition of her own, taking medicine for Alice seemed like a path she should take.

\title{
Bella
}

Bella is a 19 year old student. When asked on her reasons on why she chose medicine, Bella stated firstly of her deep affinity for helping people "who are in need" (B, Line 2, Interview). She has "seen people suffering" (B, Line 2, Interview) and she wants "to help them (B, Line 2, Interview). Her desire to help people helped influence her to take up the medical programme. Besides that, her grandmother was also suffering and she "really wanted to help" (B, Line 2, Interview). Again, similar to Alice, from all the experiences that she has seen around her, mostly of her family members, has initiated her to take up the medical programme as well.

\begin{abstract}
"I usually used to be a very weak student. That's how people see me. I didn't get any importance or people used to degrade me. Like, "You can't do anything. You're just going to be like that the whole of your life. You can't achieve anything." So I decided I should aim really high, to achieve something that people think is impossible. So I chose medicine." (B, Line 2, Interview).
\end{abstract}

From the excerpt above, people underestimated her abilities and talents during her school days and saying she would not be capable of doing anything. Tired of being judged and to prove people wrong, she decided to pursue medicine as she "really wanted to do something that is impossible" (B, Line 12, Interview). For Bella, to get into the medical programme at the most prestigious university in the country will silence her doubters and also prove to herself that she can do anything. The more people demotivated her into taking the medical programme, the more she wanted to take the programme.

"I want to challenge myself actually. I really wanted to do something that is impossible. At that time, I think almost everyone, when I said I wanted to do medicine, they'll be like "Are you sure you're going to get medicine in a medical school? Are you sure?" Something like that. And then they'll ask me, like University $Y$ [the author's institution], are you sure? It's really hard for a student to get into University $Y$, like it's an impossible story." So every day I tried to aim for that. I will think I will be in University Y. I am going to be in the medical school in University Y." (B, Line 12, Interview)

"...I said, I wanted to be a doctor. Even they said "It's very costly. I think I can't support you to do that". After that I heard from some of my seniors that I can go for these public universities under any scholarships, something like that. At that time, I really wanted to go and aim high. Every day I worked for that." (B, Line 18, Interview)

Other than the main reasons, she also said she pursued medicine because she wanted "to be rich" (B, Line 2, Interview), make her "parents proud" (B, Line 2, Interview) and use the medical programme as a platform for selfimprovement, which is "to be better in the future" (B, Line 384, Interview).

\section{Catherine}

Catherine is a 19 year old student. Personal experience from when Catherine was in her school days influenced her to pursue a career in medicine. She spoke of one of these experiences when she joined the Red Crescent Society in her secondary school. 
"So I got to know that it isn't always about ourselves. Life is not only about us but also the people around us and how we accept them in our lives. So when I met (these) people, I felt very responsible. I felt a sense of belonging with them. So I was actually interested in giving psychological advice to them. Then when I started learning about first aid and all like that, I attended some cardio-pulmonary resuscitation and basic advanced cardiac life support skills before this." (C, Line 6, Interview)

It seems that Catherine loves caring for people and is taken by the act of helping those who are sick and hurt. She enjoys and takes interest in helping people and this leads her to want to explore the medical field in more depth.

\begin{abstract}
"I have an objective before I entered this medical school. I wanted to become a surgeon or a researcher. I wanted to find at least a cure for this, the most common disease my family members had were [Disease $X$ and $Y$ ]. And my grandfather had [Disease Z] and he passed away. So I thought I can find a cure for [Disease Z] or [Disease Y] disease." (C, Line 22, Interview)
\end{abstract}

As many of her family members suffer from Diseases $\mathrm{Y}$ and $\mathrm{Z}$, especially with her father being diagnosed with Disease $\mathrm{Y}$ after her matriculation, she was determined to find a cure for these diseases. As she cannot bear to see her family members and other people suffering, she was determined to work hard in the medical programme and to find these cures.

\title{
Diana
}

Diana is a 19 year old student. Diana seemed to be very indifferent on her initial motivation for choosing medical programme as she simply wants "to give a try" (D, Line 16, Interview). She does not seem to have the passion that she could base her personal experiences and ambitions on in the line of medicine. For Diana, whichever programme she takes, she will be able to do it, and the passion will come later.

\section{"It doesn't matter. Whatever course it is, if you study well, the passion will come by itself, along with your interest. I believe in that." (D, Line 26, Interview)}

Diana was aware of the other programmes available to her only after she enrolled into medicine. Taking the medical programme was more of a matter of an opportunity to take advantage of getting good grades in her preuniversity education.

"When I am already in the medical field, I just realized that I can take other courses. There are (actually)
many other courses. Not just medicine." (D, Line 22, Interview)

\section{Elizabeth}

Elizabeth is a 19 year old student. Elizabeth's father was highly influential in her daughter's decision making on picking a "good" profession. Her father suggested that Elizabeth should take the medical programme as it is a "good" programme for her. For Elizabeth, it does not matter whatever programme she chooses in university, as long as she makes her father happy, then she will be happy.

"Becoming a doctor is good, and then he really hopes that I can pursue my study in this medicine (programme). And what makes my dad happy, makes me happy. So I chose medicine because it makes me happy." (E, Line 2, Interview)

Elizabeth also mentioned how she was only exposed to two well-known university programmes which are medicine and engineering. Hence, with the backing and advice from her father, she chose one of the only programmes she knew that will make her father proud.

"...because what I was exposed to was just doctor, engineer and nothing else. And I just know these few fields that I might choose for my next study." (E, Line 10, Interview)

\section{Fiona}

Fiona is a 19 year old student. She did not know why she had chosen medicine; she just argued that others such as accounting, finance and business were not suitable for her.

"Actually even I also don't know why I'm choosing medicine. Because I can't choose other course because I don't think other course is suitable for me like accounting, finance, business. I chose medicine 
because there is no other course that I can choose. Maybe (it's) just because of this." (F, Line 2, Interview)

Fiona performed well in Biology and enjoyed the subject. Thinking that Biology is related to medicine, Fiona later found it to be untrue. Medical study was different and more difficult from what she had imagined.

"...I really thought that Biology is really related to medicine. That's why I chose medicine. Because my Biology is I think for me is okay. But when I come through this year, I felt like yes, it's true. Biology (is) actually a little related to medicine only. Everything is different. Like Biology you study blood, everything is like superficial. But when it comes to medicine, it really considers many issues like, besides the knowledge, you (also) need to know how to deal with patients." (F, Line 12, Interview)

Fiona was also heavily influenced by her friend's opinions and advice. Her friend convinced her that medicine is a better programme than pharmacy. Hence, she agreed and eventually took up medicine even though at first she wanted to take up pharmacy.

"Actually at first, I tried to choose pharmacy. But my friend is choosing medicine. So every time when I have a meal with her, she will tell me, (trying to) convince me. Why (did) you choose pharmacy? She will give her reasons such as "do you want to deal with medicines every day or do you want to deal with real people every day? You can see many different people in the hospital like that" So lastly, maybe the peer influence, I choose the medicine." (F, Line 14 Interview)

\section{Summary}

Three observations can be made out of these six narrative analyses. These underperforming students either had no genuine interest in medicine (i.e. Diana, Elizabeth, Fiona), a mix of genuine interests and other motives (i.e. Alice, Bella), or had genuine interests in medicine (i.e. Catherine). Therefore, initial motivations of underperforming students for choosing the medical programme were either genuine, non-genuine or a mixture of both.

\section{Possible Changes of Motivation for Studying Medicine over a Period of Time}

The following radar charts (Figure 1) illustrate the changes in AMS scores before and after an interval of six months. The changes in AMS scores exhibit their possible changes of motivation over a period of time (Table 2). Three possibilities were identified. Firstly, it is possible that motivation for studying medicine can be similar. Elizabeth had similar levels of intrinsic motivation, extrinsic motivation and amotivation during the first attempt as well as in her second attempt. Secondly, extrinsic and intrinsic motivation of studying medicine could increase. For instance, Alice and Bella had higher extrinsic and intrinsic motivation during their second attempts respectively. Thirdly, motivation for studying medicine could decrease over time. Fiona was shown to have lower intrinsic and extrinsic motivation (and higher amotivation) during the second attempt. In conclusion, motivation for studying medicine may change during their study period. 


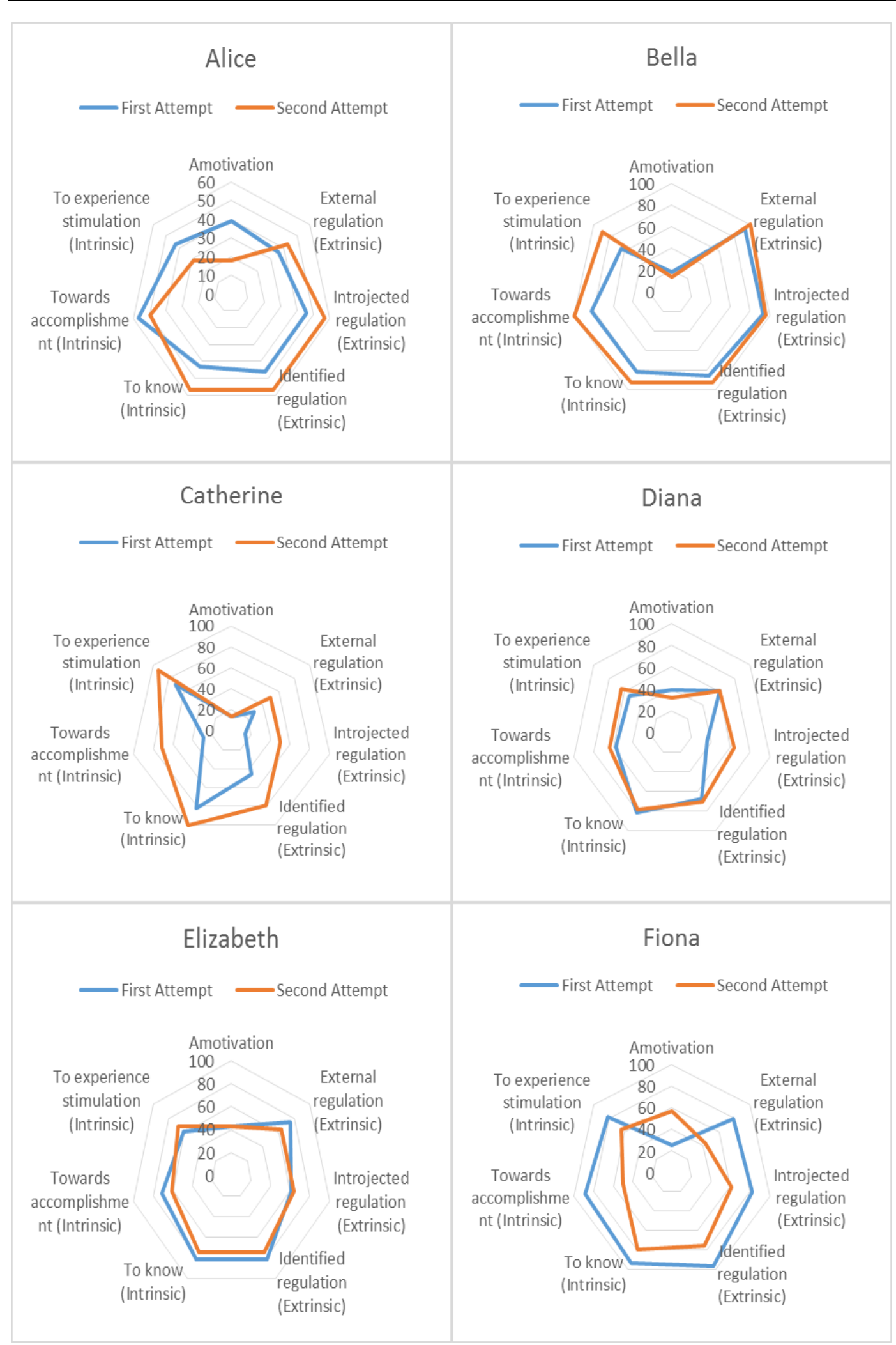

Figure 1. Changes in AMS scores before and after an interval of six months 
Table 2. Possible changes of motivation over a period of time

\begin{tabular}{ccl}
\hline No & Student & Changes \\
\hline 1 & Alice & $\begin{array}{l}\text { Extrinsic motivation increased } \\
\text { Amotivation decreased }\end{array}$ \\
\hline 2 & Bella & Intrinsic motivation increased \\
\hline 3 & Catherine & $\begin{array}{l}\text { Intrinsic motivation increased } \\
\text { Extrinsic motivation increased }\end{array}$ \\
\hline 4 & Diana & Similar level of motivations \\
\hline 5 & Elizabeth & Similar level of motivations \\
\hline 6 & Fiona & $\begin{array}{l}\text { Intrinsic motivation decreased } \\
\text { Extrinsic motivation decreased } \\
\end{array}$ \\
\hline
\end{tabular}

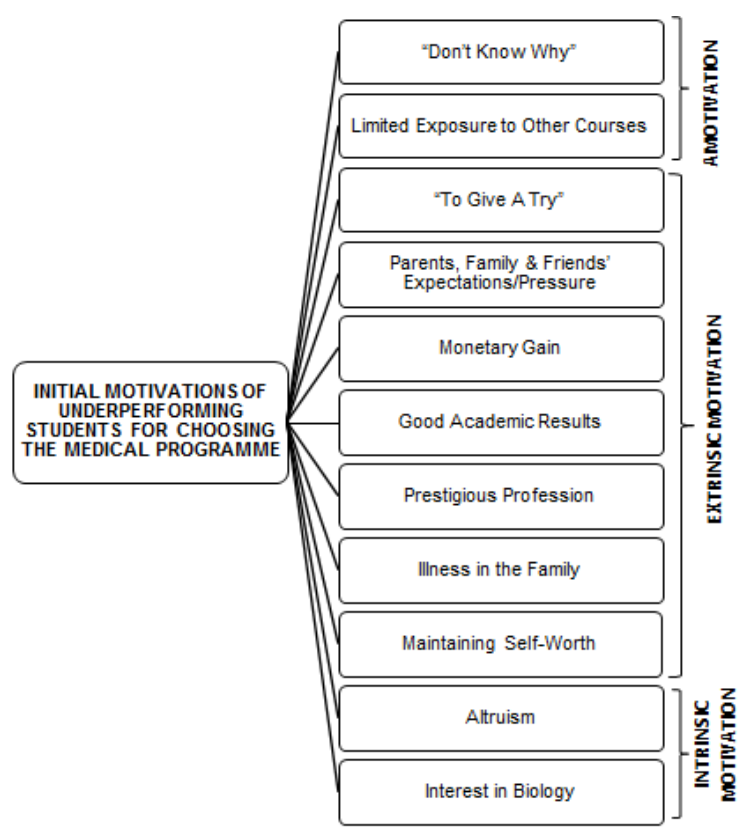

Figure 2. Categorising initial motivations for choosing the medical programme following the Self-Determination Theory

\section{DISCUSSION}

\section{Initial Motivations of Students for Choosing the Medical Programme}

We categorised initial motivations of the underperforming students for choosing the medical programme into intrinsic motivation, extrinsic motivation and amotivation. Comparison between the findings of this study (Figure 2) and past studies (Table 1) suggests similarities where there exist intrinsic motivation and extrinsic motivation among the students. Specific similarities include underperforming students who possessed extrinsic motivation such as parents or family expectation/pressure, monetary gain, prestigious profession, good academic results, illness/death in the family and maintaining one's self-worth. The underperforming students also had intrinsic motivation such as altruism and interest in Science/Biology. Initial motivations such as career prospects and vocation were not found and it seems to be reasonable because this study represents a qualitative study with merely six underperforming students.

Findings of this study suggest that postulations made by the Malaysian public (as reported earlier in the introduction) may indeed be true. In this study, some students such as Alice mentioned that her father said to "go take medicine. So I took medicine.", whereas Elizabeth said "...he really hopes that I can pursue my study in this medicine (programme). And what makes my dad happy, makes me happy." indicating one of the aforementioned reasons which are the parents' expectations or pressures. This suggests a cultural difference between the Eastern and Western countries. While family pressure is likely to be more common among medical students in Eastern countries (AlHemiary et al., 2017), Western studies discovered more genuine interests (Gąsiorowski et al., 2015; Millan et al., 
2005). A likely explanation would be due to the cultural differences where it is a norm for Eastern children to show respect by obeying their parents in most life choices (Abdullah \& Pederson, 2003; Shin, Lee, \& Ha, 2017).

Further explanation is that people from different cultures have varying construals (e.g., perception, understanding or interpretations) of self, others and the dependence between these two variables. Interestingly, these construals can influence an individual's motivation, emotion and cognition (Markus \& Kitayama, 1991) and these differences have been observed in the self-construal of people in the East and West (Kitayama, Markus, Matsumoto, \& Norasakkunkit, 1997). It has been opined that Western people are more geared towards individualism (independent self-construal) which focuses on personal success and are motivated in expressing themselves (Nishimura \& Sakurai, 2017). In comparison, Eastern people have dependent self-construals (collectivism) where they are keen to achieve goals that are shared with others in their social contexts. This is conformed by Bao \& Lam (2008) where Chinese children were motivated to do the tasks or goals chosen by parents as they felt related or attached to their parents. When one of the basic human psychological needs (i.e., relatedness) is fulfilled, children are able to internalise their parents' choice as their own choice (Bao \& Lam, 2008). Subsequently, they are intrinsically motivated to do the tasks.

On the contrary, our study also identified amotivation as one of the initial motivations for choosing the medical programme. Firstly, some of the students admitted that they were unsure which career pathway to undertake after completing their pre-university education. Secondly, they had limited exposure to university programmes available to them. It seemed either they had not taken the sufficient initiatives to explore career opportunities or career guidance was lacking in their schools. This study is also unique in a sense that the results reported cases of underperforming students admitting they had amotivation when applying to the medical school. Our findings may imply that in order to curb these issues, it is recommended that the national education system could facilitate the transition process from high school to university. Career guidance is essential in creating awareness on the demanding nature of the medical programme (e.g. heavy workload and highly stressful environment) and faculty members can meet and educate high school students to have dialogues on the medical programme and its career life (Juma, Abas, \& Banu, 2016). These visits may prepare students for the crux of becoming a medical doctor which emphasizes on intrinsic motivation (i.e. self-directed learning and lifelong learning).

It is generally recognised that intrinsic motivation would positively influence the academic performance of the student (Kusurkar et al., 2011; Shrestha \& Pant, 2018; ten Cate, Kusurkar, \& Williams, 2011). However, the argument is inconclusive for this study. Even with intrinsic motivation prior to medical school, Bella still underperformed. We ruled out cognitive inabilities of the student as an explanation as these students were selected based on their prior excellent academic results. Hence, this proves that students' initial motivation to choose the medical programme may not matter after all, as all students have been interviewed for the admission selection.

Initial motivations of students for studying medicine are widely used by medical schools as one of the criteria in which the interviewers try to identify during admission (Wouters, Bakker, van Wijk, Croiset, \& Kusurkar, 2014). It is generally expected for admission interviews to ask questions such as "Why do you want to become a doctor?' or in other varied manners, 'what experiences have you had that has lead you to believe you would be a good doctor?' to potential candidates in order to select the most intrinsically motivated (Eva, Rosenfeld, Reiter, \& Norman, 2004). As medical schools are unlikely to offer a place to candidates who possess low intrinsic motivation, candidates would be expected to give favourable answers to the interviewers (Wouters, Croiset, Galindo-Garre, \& Kusurkar, 2016). Internet search engines such as Google, Yahoo! and Bing have a collection of interview techniques and commonly asked questions for candidates to practice beforehand, and these candidates would be able to feign having intrinsic motivation. On the 11 April 2018, Google returned 1,210,000 results on the search terms "medical school interview tips". However, this poses challenges in differentiating candidates who truly possess intrinsic motivation from those who are merely pretending to possess one during the admission interviews. There is also a worry that a candidate's intrinsic motivation to study medicine could be inspired by the demanding selection procedures (e.g. cognitive test, interview) which only temporarily increase his or her motivation (Wouters et al., 2016).

\section{Possible Changes of Motivation for Studying Medicine over a Period of Time}

We still argue motivation is important, and our findings suggest that motivation could increase or decrease. As motivation is dynamic and fluctuating in nature, it could be moulded through enhancing student autonomy, competence and relatedness, which are the basic psychological needs for intrinsic motivation according to the SelfDetermination Theory (Kusurkar et al., 2011). Motivation is also affected by four factors: situation (alludes to the environmental factors surrounding the individual), mood (emotional state), goal (purpose and targets) and tool (what one needs to possess in order to achieve the goal that has been set) (Yousefy et al., 2012). Meanwhile, strategies to promote motivation could be developed using the concepts of self-efficacy (e.g., mastery, competence, confidence) (Bandura, 1977) and self-regulated learning (e.g. strategy use) (Pintrich \& De Groot, 1990). 
It is recommended that students themselves as well as the educators should be involved in modifying motivation among medical students. Burnout among medical students has been commonly reported as pursuing a medical degree is known to be highly stressful (Almeida, Souza, Almeida, Almeida, \& Almeida, 2016; Cohen et al., 2005; Győrffy et al., 2016; Lyndon et al., 2017; Pagnin et al., 2013; Park et al., 2012). Therefore, after entering medical school, it is imperative for students to properly reflect on why they want to become a doctor, and if possible, they should possess strong motivation. This is so that medical students could cope better with the various challenges awaiting them in their studies (Győrffy et al., 2016).

Though some may argue that students should have known the answer to 'Why do I want to become a doctor?' before applying to medical school, it may not be practical. Students are unlikely to have been exposed to the exhausting nature of the programme before enrolling into the medical schools. Furthermore, misleading images of the medical profession are often found in television medical dramas (Czarny, Faden, \& Sugarman, 2010; Strauman \& Goodier, 2008). In one study, half of the high school students were observed to be strongly influenced by TV medical dramas to pursue a medical programme (McHugh et al., 2011). These medical dramas often romanticise the true nature of the job such as the heavy workloads and working in a highly stressful environment, thus, further leading to more misconceptions on the reality of the medical profession.

As mentioned, medical educators also play a role. Although students should be mainly responsible for their decisions as adults, medical educators also hold social responsibilities in producing committed and passionate doctors. This effort is important as competencies of medical graduates also encompass the affective domains in addition to the cognitive and psychomotor domains. Hence, focusing on how motivation could develop and why it changes are more meaningful for medical educators in fostering motivation in education (Turner \& Patrick, 2008). One of the approaches is to exercise the use of a reflective portfolio. This exercise helps medical students to construct their professional identity and enables the growth of motivation to study medicine (Wong \& Trollope-Kumar, 2014). On the other hand, recent findings also showed that early clinical exposure increased motivation to study medicine among the students (Govindarajan et al., 2017; Nimkuntod, Kaewpitoon, Uengarporn, Ratanakeereepun, \& Tongdee, 2015)

Medical schools are responsible to create a conducive education environment and there should be a good support system for students who get stressed or demotivated (Roff et al., 1997). Researching into motivation was not only to profile students' motivation, but alerting the medical teachers, their educational roles include to facilitate and manage students with a wider understanding of education theories (Sobral, 2004).

\section{Strengths and Limitations of the Study}

Qualitative studies regarding student motivation in pursuing medicine are available, (McHarg et al., 2007; Wouters et al., 2014, 2017) but limited. Furthermore, this present study may be one of the very few qualitative studies that investigates both, the initial motivation and changes of motivations over a period of time of underperforming medical students as they are a minority group. Hence, these students would need greater help in remediating themselves.

There were methodological considerations. Firstly, in the data collection processes, dialogues with students on the benefits (i.e., reflection) they received as well as the management of the confidentiality seemed to yield honest and rich information. Triangulation of analysts, audit trails and describing the context of the study also helped to enhance the trustworthiness of the findings. Secondly, we understand that as remedial coaches for the student support, we may be biased towards these students. An example of this would be making an assumption that underperforming students are lazy and asked leading questions. We encouraged students to honestly express themselves. Thirdly, all Year 1 underperforming students were interviewed. During the interview, we asked the same questions differently (e.g., why did you choose to study medicine? Some students said they choose medicine because they scored excellent results in the pre-university) and we prompted the students following their initial responses. Hence, it was argued that the data is rich and descriptive. Lastly, the students did not check the interview transcripts and findings and we understand that this was a limitation. However, the interviews were transcribed verbatim.

One of our limitations was how some of the data were collected retrospectively. For instance, interviews on students' initial motivation for choosing the medical programme were conducted only after they failed Year 1, which could be questionable. However, data collection upon entering the medical school may also be questionable as students may want to portray a positive image in front of the interviewers instead of revealing they possessed no motivation or were extrinsically motivated. Although data was collected retrospectively, we managed to build rapport and trust with the underperforming students where we believed that they had given an honest reflection of themselves. Besides that, this present study did not investigate the possibility that high performing students may also have amotivation and/or low intrinsic motivation to study medicine. Therefore, future qualitative studies should consider comparing the motivation between high performing and underperforming students to investigate 
how and why motivations for choosing medicine have influenced their learning experiences. Lastly, large scale quantitative studies to measure changes in motivation to study medicine over a period of time would help to backup (otherwise rebut) our qualitative findings that the changes in motivation are possible.

\section{CONCLUSION}

This study revealed that initial motivations of underperforming students for choosing the medical programme may not matter to their academic failures. On the other hand, we still argue that student motivation is important. We believe that genuine interest in medicine should be innate among all medical students and medical practitioners alike. Hence, with the newfound results of this study where a shift in student motivation is possible through a period of time, greater efforts to nurture intrinsic motivation among students should be encouraged in medical schools.

\section{ACKNOWLEDGEMENTS}

The research was funded by the University of Malaya Research Fund Assistance (BKP) BK023-2016, the High Impact Research Chancellery Grant UM.C/625/1/HIR/ASH/025 from the University of Malaya and the University of Malaya Learning Improvement and Teaching Enhancement Research (UM-LiTeR) RU002E-2016O. The authors thanked the PSG-FAIMER Regional Institute for their suggestions to improve the study.

\section{REFERENCES}

Abdullah, A., \& Pederson, P. B. (2003). Understanding multicultural Malaysia delights, puzzles and irritations. Malaysia: Pearson Malaysia Sdn. Bhd.

Al-Hemiary, N., Al-Nuaimi, A. S., Al-Saffar, H., \& Randall, I. (2017). Why people apply to medical school in Iraq? Journal of Medical Education and Curricular Development, 4, 1-5. https:/ / doi.org/10.1177/2382120517726997

Almeida, G. d. C., Souza, H. R. d., Almeida, P. C. d., Almeida, B. d. C., \& Almeida, G. H. (2016). The prevalence of burnout syndrome in medical students. Archives of Clinical Psychiatry (São Paulo), 43(1), 6-10. https:/ / doi.org/10.1590/0101-60830000000072

An, M., Kusurkar, R., Li, L., Xiao, Y., Zheng, C., Hu, J., \& Chen, M. (2017). Measurement invariance of the strength of motivation for medical school: a multi-group confirmatory factor analysis. BMC Medical Education, 17(1), 116. https:// doi.org/10.1186/s12909-017-0958-4

Ayuob, N. N., Bahumdain, S. Z., AL-Najei, Z. A., Khobrani, F. M., \& El Deek, B. S. (2015). Becoming a doctor, what is behind this decision? A comparative study between governmental and private medical school in Saudi Arabia. Journal of Contemporary Medical Education, 3(4), 155. https:/ / doi.org/10.5455/jcme.20151222112334

Bandura, A. (1977). Self-efficacy: Toward a unifying theory of behavioral change. Psychological Review, 84(2), 191. https:/ / doi.org/10.1037/0033-295X.84.2.191

Bao, X. h., \& Lam, S. f. (2008). Who makes the choice? Rethinking the role of autonomy and relatedness in Chinese children's motivation. Child Development, 79(2), 269-283. https:// doi.org/10.1111/j.1467-8624.2007.01125.x

Cohen, D., Rollnick, S., Smail, S., Kinnersley, P., Houston, H., \& Edwards, K. (2005). Communication, stress and distress: Evolution of an individual support programme for medical students and doctors. Medical Education, 39(5), 476-481. https:// doi.org/10.1111/j.1365-2929.2005.02122.x

Crossley, M. L., \& Mubarik, A. (2002). A comparative investigation of dental and medical student's motivation towards career choice. British Dental Journal, 193(8), 471-473. https:/ / doi.org/10.1038/sj.bdj.4801599

Cruez, A. F. (7 September 2014). 20\% Malaysian medical students lack qualification. The Sun Daily. Retrieved from http://www.thesundaily.my/news/1162028

Czarny, M. J., Faden, R. R., \& Sugarman, J. (2010). Bioethics and professionalism in popular television medical dramas. Journal of Medical Ethics, 36(4), 203-206. https:/ / doi.org/10.1136/jme.2009.033621

Deci, E. L., \& Ryan, R. M. (2000). The" what" and" why" of goal pursuits: Human needs and the self-determination of behavior. Psychological Inquiry, 11(4), 227-268. https:/ / doi.org/10.1207/S15327965PLI1104_01

Deci, E. L., \& Ryan, R. M. (2008). Self-determination theory: A macrotheory of human motivation, development, and health. Canadian Psychology, 49(3), 182-185. https:/ / doi.org/10.1037/a0012801

Del-Ben, C. M., Machado, V. F., Madisson, M. M., Resende, T. L., Valério, F. P., \& Troncon, L. E. D. A. (2013). Relationship between academic performance and affective changes during the first year at medical school. Medical Teacher, 35(5), 404-410. https:/ / doi.org/10.3109/0142159X.2013.769675 
Diwan, V., Minj, C., Chhari, N., \& De Costa, A. (2013). Indian medical students in public and private sector medical schools: are motivations and career aspirations different?-studies from Madhya Pradesh, India. BMC Medical Education, 13(1), 127. https:/ / doi.org/10.1186/1472-6920-13-127

Eva, K. W., Rosenfeld, J., Reiter, H. I., \& Norman, G. R. (2004). An admissions OSCE: the multiple mini-interview. Medical Education, 38(3), 314-326. https:/ / doi.org/10.1046/j.1365-2923.2004.01776.x

Feri, R., Soemantri, D., \& Jusuf, A. (2016). The relationship between autonomous motivation and autonomy support in medical students' academic achievement. International Journal of Medical Education, 7, 417. https:/ / doi.org/10.5116/ijme.5843.1097

Gąsiorowski, J., Rudowicz, E., \& Safranow, K. (2015). Motivation towards medical career choice and future career plans of Polish medical students. Advances in Health Sciences Education, 20(3), 709-725. https://doi.org/10.1007/s10459-014-9560-2

Girasek, E., Molnár, R., Eke, E., \& Szócska, M. (2011). The medical career choice motivations-Results from a Hungarian study. Open Medicine, 6(4), 502-509. https:/ / doi.org/10.2478/s11536-011-0034-0

Goel, S., Angeli, F., Dhirar, N., Singla, N., \& Ruwaard, D. (2018). What motivates medical students to select medical studies: a systematic literature review. BMC Medical Education, 18(1), 16. https://doi.org/10.1186/s12909018-1123-4

Govindarajan, S., Vasanth, G., Kumar, P. A., Priyadarshini, C., Radhakrishnan, S. S., Kanagaraj, V. et al. (2017). Impact of a comprehensive early clinical exposure program for preclinical year medical students. Health Professions Education. Retrieved from https:/ / doi.org/10.1016/j.hpe.2017.06.002

Győrffy, Z., Birkás, E., \& Sándor, I. (2016). Career motivation and burnout among medical students in Hungarycould altruism be a protection factor? BMC Medical Education, 16(1), 182. https://doi.org/10.1186/s12909016-0690-5

Heikkilä, T. J., Hyppölä, H., Vänskä, J., Aine, T., Halila, H., Kujala, S. et al. (2015). Factors important in the choice of a medical career: a Finnish national study. BMC Medical Education, 15(1), 169. https:/ / doi.org/10.1186/s12909-015-0451-x

Hurst, S. A. (2014). Eroding students' rural motivation: First do no harm. Swiss Medical Weekly, 144, w14020. https://doi.org/10.4414/smw.2014.14020

Hyppölä, H., Kumpusalo, E., Neittaanmäki, L., Mattila, K., Virjo, I., Kujala, S. et al. (1998). Becoming a doctor --Was it the wrong career choice? Social Science \& Medicine, 47(9), 1383-1387. https://doi.org/10.1016/S02779536(98)00208-1

Juma, F. Z., Abas, T., \& Banu, S. (2016). The transition from high school to university: A medical student's perspective. Advances in Medical Education and Practice, 7, 517. https:/ / doi.org/10.2147/AMEP.S114753

Khami, M., Murtomaa, H., Jafarian, M., Vehkalahti, M., \& Virtanen, J. (2008). Study motives and career choices of Iranian dental students. Medical Principles and Practice, 17(3), 221-226. https:/ / doi.org/10.1159/000117796

Kitayama, S., Markus, H. R., Matsumoto, H., \& Norasakkunkit, V. (1997). Individual and collective processes in the construction of the self: self-enhancement in the United States and self-criticism in Japan. Journal of Personality and Social Psychology, 72(6), 1245. https:/ / doi.org/10.1037/0022-3514.72.6.1245

Kusurkar, R. A., Croiset, G., Galindo-Garré, F., \& Ten Cate, O. (2013). Motivational profiles of medical students: association with study effort, academic performance and exhaustion. BMC Medical Education, 13(1), 87. https:// doi.org/10.1186/1472-6920-13-87

Kusurkar, R. A., Ten Cate, T. J., van Asperen, M., \& Croiset, G. (2011). Motivation as an independent and a dependent variable in medical education: A review of the literature. Medical Teacher, 33(5), $242-262$. https:// doi.org/10.3109/0142159x.2011.558539

Lee, S. S., Foong, C. C., Choon, S. K., \& Jamuna, V. (in press). Language in medicine: a necessity or redundancy for medical undergraduates? International Medical Journal.

Lyndon, M. P., Henning, M. A., Alyami, H., Krishna, S., Zeng, I., Yu, T.-C., \& Hill, A. G. (2017). Burnout, quality of life, motivation, and academic achievement among medical students: A person-oriented approach. Perspectives on Medical Education, 6(2), 108-114. https:/ / doi.org/10.1007/s40037-017-0340-6

Markus, H. R., \& Kitayama, S. (1991). Culture and the self: Implications for cognition, emotion, and motivation. Psychological Review, 98(2), 224. https:/ / doi.org/10.1037/0033-295X.98.2.224

McHarg, J., Mattick, K., \& Knight, L. V. (2007). Why people apply to medical school: implications for widening participation activities. Medical Education, 41(8), 815-821. https://doi.org/10.1111/j.1365-2923.2007.02798.x 
McHugh, S., Corrigan, M., Sheikh, A., Lehane, E., Broe, P., \& Hill, A. (2011). A study of the factors influencing school-going students considering medical careers. The Surgeon, 9(4), 191-194. https:/ / doi.org/10.1016/j.surge.2010.09.005

Merriam, S. (2009). Qualitative research: A guide to design and implementation San Fransisco: John Willey \& Sons Inc.

Millan, L. R., Azevedo, R. S., Rossi, E., De Marco, O. L. N., Millan, M. P. B., \& Arruda, P. C. V. d. (2005). What is behind a student's choice for becoming a doctor? Clinics, 60(2), 143-150. https://doi.org/10.1590/S180759322005000200011

Molnár, R., Nyári, T., Hazag, A., Csinády, A., \& Molnár, P. (2008). Career choice motivations of medical students and some characteristics of the decision process in Hungary. Open Medicine, 3(4), 494-502. https://doi.org/10.2478/s11536-008-0063-5

Nimkuntod, P., Kaewpitoon, S., Uengarporn, N., Ratanakeereepun, K., \& Tongdee, P. (2015). Perceptions of medical students and facilitators of an early clinical exposure instructional program. Journal of the Medical Association of Thailand, 98(Suppl 4), S64-70.

Nishimura, T., \& Sakurai, S. (2017). Longitudinal changes in academic motivation in Japan: Self-determination theory and East Asian cultures. Journal of Applied Developmental Psychology, 48, 42-48. https:/ / doi.org/10.1016/j.appdev.2016.11.004

Pagnin, D., De Queiroz, V., Oliveira Filho, M. A. D., Gonzalez, N. V. A., Salgado, A. E. T., Oliveira, B. C. E. et al. (2013). Burnout and career choice motivation in medical students. Medical Teacher, 35(5), 388-394. https:// doi.org/10.3109/0142159X.2013.769673

Parameshvaradeva, M. (1981). Career choices of Malaysian medical students. Medical Journal of Malaysia, 36(3), 188192.

Park, J., Chung, S., An, H., Park, S., Lee, C., Kim, S. Y. et al. (2012). A structural model of stress, motivation, and academic performance in medical students. Psychiatry Investigation, 9(2), 143-149. https:/ / doi.org/10.4306/pi.2012.9.2.143

Pintrich, P. R., \& De Groot, E. V. (1990). Motivational and self-regulated learning components of classroom academic performance. Journal of Educational Psychology, 82(1), 33. https://doi.org/10.1037/00220663.82.1.33

Pruthi, S., Pandey, R., Singh, S., Aggarwal, A., Ramavat, A., \& Goel, A. (2013). Why does an undergraduate student choose medicine as a career. The National Medical Journal of India, 26, 147-149.

Puljak, L., Kraljevic, J. B., Latas, V. B., \& Sapunar, D. (2007). Demographics and motives of medical school applicants in Croatia. Medical Teacher, 29(8), 227-234. https:/ / doi.org/10.1080/01421590701551714

Razali, S. M. (1996). Medical school entrance and career plans of Malaysian medical students. Medical Education, 30(6), 418-423. https: / / doi.org/10.1111/j.1365-2923.1996.tb00861.x

Riessman, C. K. (2005). Narrative analysis. Thousand Oaks, California: Sage Publications.

Roff, S., McAleer, S., Harden, R. M., Al-Qahtani, M., Ahmed, A. U., Deza, H. et al. (1997). Development and validation of the Dundee ready education environment measure (DREEM). Medical Teacher, 19(4), 295-299. https:// doi.org/10.3109/01421599709034208

Ryan, R. M., \& Deci, E. L. (2000a). Intrinsic and extrinsic motivations: Classic definitions and new directions. Contemporary Educational Psychology, 25(1), 54-67. https:/ / doi.org/10.1006/ceps.1999.1020

Ryan, R. M., \& Deci, E. L. (2000b). Self-determination theory and the facilitation of intrinsic motivation, social development, and well-being. American Psychologist, 55(1), 68-78. https://doi.org/10.1037//0003066x.55.1.68

Schutte, T., Tichelaar, J., Dekker, R. S., Thijs, A., de Vries, T. P., Kusurkar, R. A. et al. (2017). Motivation and competence of participants in a learner-centered student-run clinic: An exploratory pilot study. BMC Medical Education, 17(1), 23. https:/ / doi.org/10.1186/s12909-017-0856-9

Shahabuddin, S. H. (1986). Career choice of final-year female medical students at Universiti Kebangsaan Malaysia (UKM). Medical Journal of Malaysia, 41(4), 327-330.

Shankar, N., Singh, S., Gautam, S., \& Dhaliwal, U. (2013). Motivation and preparedness of first semester medical students for a career in medicine. Indial Journal of Physiology and Pharmacology, 57, 432-438.

Shin, S., Lee, J.-K., \& Ha, M. (2017). Influence of career motivation on science learning in Korean high-school students. EURASIA Journal of Mathematics Science and Technology Education, 13(5), 1517-1538. https:/ / doi.org/10.12973/eurasia.2017.00683a 
Shrestha, L., \& Pant, S. N. (2018). Motivational Profiles of Medical Students of Nepalese Army Institute of Health Sciences. Journal of Nepal Health Research Council, 15(3), 252-257. https:/ / doi.org/10.3126/jnhrc.v15i3.18850

Skatova, A., \& Ferguson, E. (2014). Why do different people choose different university degrees? Motivation and the choice of degree. Frontiers in Psychology, 5, 1244. https:/ / doi.org/10.3389/fpsyg.2014.01244

Sobral, D. T. (2004). What kind of motivation drives medical students' learning quests? Medical Education, 38(9), 950-957. https:// doi.org/10.1111/j.1365-2929.2004.01913.x

Strauman, E., \& Goodier, B. C. (2008). Not your grandmother's doctor show: A review of Grey's Anatomy, House, and Nip/Tuck. Journal of Medical Humanities, 29(2), 127-131. https:/ / doi.org/10.1007/s10912-008-9055-3

ten Cate, O. T. J., Kusurkar, R. A., \& Williams, G. C. (2011). How self-determination theory can assist our understanding of the teaching and learning processes in medical education. AMEE guide No. 59. Medical Teacher, 33(12), 961-973. https:/ / doi.org/10.3109/0142159X.2011.595435

Turner, J. C., \& Patrick, H. (2008). How does motivation develop and why does it change? Reframing motivation research. Educational Psychologist, 43(3), 119-131. https:/ / doi.org/10.1080/00461520802178441

Vaglum, P., Wiers-Fenssen, F., \& Ekeberg, Ø. (1999). Motivation for medical school: the relationship to gender and specialty preferences in a nationwide sample. Medical Education, 33, $236-242$. https:/ / doi.org/10.1046/j.1365-2923.1999.00293.x

Vallerand, R. J., Pelletier, L. G., Blais, M. R., Briere, N. M., Senecal, C., \& Vallieres, E. F. (1992). The Academic Motivation Scale: A measure of intrinsic, extrinsic, and amotivation in education. Educational and Psychological Measurement, 52(4), 1003-1017. https:/ / doi.org/10.1177/0013164492052004025

Vallerand, R. J., Pelletier, L. G., Blais, M. R., Brière, N. M., Senecal, C., \& Vallieres, E. F. (1993). On the assessment of intrinsic, extrinsic, and amotivation in education: Evidence on the concurrent and construct validity of the Academic Motivation Scale. Educational and Psychological Measurement, 53(1), 159-172. https:/ / doi.org/10.1177/0013164493053001018

Wong, A., \& Trollope-Kumar, K. (2014). Reflections: an inquiry into medical students' professional identity formation. Medical Education, 48(5), 489-501. https:/ / doi.org/10.1111/medu.12382

Woodward, A., Thomas, S., Jalloh, M. B., Rees, J., \& Leather, A. (2017). Reasons to pursue a career in medicine: a qualitative study in Sierra Leone. Global Health Research and Policy, 2(1), 34. https:/ / doi.org/10.1186/s41256017-0054-7

Wouters, A., Bakker, A. H., van Wijk, I. J., Croiset, G., \& Kusurkar, R. A. (2014). A qualitative analysis of statements on motivation of applicants for medical school. BMC Medical Education, 14(1), 200. https:/ / doi.org/10.1186/1472-6920-14-200

Wouters, A., Croiset, G., Galindo-Garre, F., \& Kusurkar, R. A. (2016). Motivation of medical students: selection by motivation or motivation by selection. BMC Medical Education, 16(1), 37. https://doi.org/10.1186/s12909016-0560-1

Wouters, A., Croiset, G., Isik, U., \& Kusurkar, R. A. (2017). Motivation of Dutch high school students from various backgrounds for applying to study medicine: A qualitative study. British Medical Journal Open, 7(5), e014779. https:/ / doi.org/10.1136/bmjopen-2016-014779

Yin, R. K. (2003). Case study research: Design and methods (3rd ed.). Thousand Oaks, California: SAGE.

Yousefy, A., Ghassemi, G., \& Firouznia, S. (2012). Motivation and academic achievement in medical students. Journal of Education and Health Promotion, 1, 4. https:/ / doi.org/10.4103/2277-9531.94412

Yusoff, M. S. B., Rahim, A. F. A., Baba, A. A., \& Esa, A. R. (2011). Medical student selection process and its preadmission scores association with the new students' academic performance in Universiti Sains Malaysia. International Medical Journal, 18(4), 327-331.

\section{http://www.ejmste.com}

